\title{
Del espacio a la espacialidad en textos medievales
}

\section{Space and Spatiality in Medieval Texts}

\author{
Samantha Escobar Fuentes \\ Benemérita Universidad Autónoma de Puebla \\ escobarfuentes@gmail.com
}

\section{RESUMEN}

El presente trabajo busca, por un lado, mostrar que a pesar de la ingente bibliografía dedicada al estudio del espacio literario el uso del término resulta ambiguo cuando no escasamente definido. Por otro lado, se pretende ampliar el panorama de recursos espaciales más allá de la descripción y reconocer otras formas de construcción de la espacialidad en obras literarias, específicamente las medievales. La propuesta de la espacialidad aquí definida está planteada en términos de una gramática y una semántica que permitan identificar y contextualizar diferentes elementos lingüísticos y literarios que intervienen en la construcción de la espacialidad en la obra literaria, puesto que reconocemos que tanto la idea de espacio como su forma de representarse literariamente se ha historizado y por tanto no es una, unívoca ni universal.

Palabras Clave: espacio, espacialidad, literatura medieval, gramática de la espacialidad, semántica de la espacialidad

\begin{abstract}
Being aware of the wide bibliography devoted to the study of the space in literature, this work pretends, in the first place, to make a review of much of such bibliography in order to show that the term is either ambiguous or scarcely defined. Having done so we came up with the concept of "spatiality" instead of that of "space" since we acknowledge that the construction of space may vary from author to author, from time to time, or from genre to genre and thus require a more comprehensive approach. Within this spatiality we would distinguish between a "grammar" and a "semantics" of the spatiality which would be useful to identify and interpret the spatial elements of the literary work in its context. By doing so we intend here to point at other literary and linguistic elements of the literary work than description which may enforce the study of the medieval texts in a more comprehensive way, especially, medieval ones.
\end{abstract}

KEYWORDS: space, spatiality, medieval literature, spatiality grammar, spatiality semantics

FECHA DE RECEPCIÓN: $31 / 05 / 2020$

FECHA DE ACEPTACión: 22/08/2020 
"El espacio es dialéctico, es resultado y causa, producto y productor pero más importante, es una apuesta: histórica, poética, social”

PINeT on gran economía espacial contará Çifar" a Grima el "Cuento del medio amigo" haciendo referencia a la ciudad sólo por su nombre, sin dar mayores detalles. ${ }^{2}$ Con la misma brevedad, hará referencia el narrador de Cárcel de amor a los "valles hondos y escuros que se hacen en la Sierra Morena" (Cárcel de amor, 4) donde encuentra al caballero y al preso que se vuelven motivo de su narración. "En algún lugar de la Mancha” (Don Quijote, 69), por sucinta que sea la mención, es donde sucede la historia de don Quijote. Parecería en estos ejemplos que el lugar donde ocurren los sucesos que se narran sirve únicamente de telón de fondo de la acción y por tanto no es necesario reparar en ellos - a menos claro, que se tratara de algún relato de viajes donde el espacio sí resulta primordial-. Es innegable, no obstante, que no hay narración que suceda en el vacío y que detrás de la sola mención a un lugar hay rasgos de espacialidad ${ }^{3}$ que son dignos de ser estudiados.

El espacio no ha sido siempre el mismo: su teorización ha pasado por procesos de historización que han dado como resultado una pluralidad de percepciones, acercamientos, definiciones y características. De ahí que este trabajo proponga un acercamiento al estudio de la espacialidad y no al espacio ya que nos parece que el fenómeno espacial dentro de la literatura varía de género en género, de una época a otra, de una corriente a otra, de un autor a otro, de una estética a otra. Recordemos las palabras de Aníbal A. Biglieri que en su artículo "Espacios narrativos medievales: propuestas para su estudio", señala que

la representación del espacio en la literatura medieval española es más rica y más matizada de lo que prodría creerse, si, como quedó apuntado, no se la limita solamente a las descripciones y si se admite una amplia gama de

${ }^{1}$ Aunque también se puede escribir como Cifar o Zifar, se cita aquí siguiendo la edición de Marilyn Olsen de El libro del cavallero Çifar consignada en la bibliografía.

${ }^{2}$ Economía recurrente en todo el texto, con algunas excepciones como en el "Relato del caballero atrevido".

${ }^{3} \mathrm{Al}$ respecto de la importancia de su estudio Robert T. Tally Jr., señala "over the past few decades, spatiality has become a key concept for literary and cultural studies" (Spatiality, 3). 
posibilidades que incluyen la fusión y multiplicación de los espacios de la ficción postmodernista, la percepción de éstos a través de los personajes y no siempre de un narrador 'omnisciente', como los relatos modernistas, o la visión concreta y estable, propia de un realismo decimonónico (28).

Así las cosas, con un panorama tan diverso, lo que este trabajo pretende es revisar diferentes posturas de análisis literario del espacio para aterrizar en una propuesta que pueda dar cuenta de las características espaciales particulares de las obras en su contexto, ya que si bien coincidimos en que la descripción es "la forma discursiva privilegiada para generar ilusión del espacio" (Pimentel, El espacio en la ficción, 7-8), consideramos necesario recuperar otros elementos textuales (lingüísticos y literarios) igual de válidos quizá sólo menos evidentes.

\section{ESPACIO Y LITERATURA}

En El espacio en la ficción — texto de consulta obligada sobre el asunto- Luz Aurora Pimentel señala con mucha razón que resulta inconcebible "un acontecimiento narrado que no esté inscrito en un espacio descrito" (7) (las cursivas son del original), de manera que lo narrado es tan relevante como la descripción del lugar donde sucede. Dejando entonces de lado la dicotomía tiempo/espacio en la obra literaria ${ }^{4}$ ya solventada por conceptos como el del cronotopo de Bajtín, este trabajo intenta recuperar otras características de la obra literaria (la medieval en particular) para el estudio del espacio.

La literatura, más que repensar el espacio, se ha enfocado en su representación. Las obras literarias, bajo el concepto de mimesis de la realidad que ya apuntaba Aristóteles, operan con mecanismos de espacialidad que replican o desarticulan dichas concepciones, pero teniéndolas siempre como referente. De este modo, aunque la literatura recurre a premisas propias, distintas a las de la realidad física extraliteraria, el espacio, sus formas y dimensiones, entre otras cosas, nos resultan cognoscibles. Estas formas de representación del espacio no son casuales; para Robert T. Tally Jr. "maybe literature helps readers get a sense of the worlds in which others have lived, currently live, or will live

\footnotetext{
${ }^{4}$ La concepción de la narración, como sucesión de eventos en el tiempo llevó a privilegiar el aspecto temporal sobre el espacial bajo la idea de que cuando había espacio, es decir, descripción, la narración se detenía, de manera que tiempo y espacio eran hasta cierto punto excluyentes.
} 
in times to come. From a writer's perspective, maybe literature provides a way of mapping the spaces encountered or imagined in the author's experience" (Spatiality, 2).

Aunque de unos años para acá la bibliografía de artículos, libros o tesis sobre el espacio literario ha aumentado exponencialmente, el asunto no es nuevo. Al respecto, parece necesario puntualizar dos cosas: 1) la mayoría de los trabajos parten de una concepción del espacio muy amplia, en la que de pronto cabe todo; y 2) en consecuencia sus abordajes son, en ocasiones, bastante disímiles; en palabras de Gabriel Zoran, el uso del término es "far from unambiguous" (“Towards a Theory”, 309).

Haciendo una revisión con un criterio más o menos cronológico podríamos citar trabajos como los de Mijaíl M. Bajtín que, en "Las formas del 134 tiempo y el cronotopo en la novela" de 1938, ${ }^{5}$ desarrolla la unión indisociable entre tiempo y espacio en lo que llama "cronotopo artístico literario". Joseph Frank, en 1945, se ocupa también del tema, estudiando lo que llama la "forma espacial" de la escritura que adjudicó a los poetas modernos, sólo para que poco tiempo después W. J. T. Mitchell hiciera notar que dicha espacialidad es casi tan antigua como la escritura, enfatizando asimismo la unión entre espacio y tiempo. Diez años después, en 1955, Maurice Blanchot, en El espacio literario abordaría aquel de la creación artística. Dos años más tarde, llegaría La poética del espacio de Gastón Bachelard, que usando como base la casa, establecería la noción de topofilia.

Todos estos trabajos son sólo algunos de los más conocidos entre muchos más, que con fines prácticos podrían ser agrupados en dos grandes categorías dependiendo del tipo de acercamiento que proponen al espacio: 1) aquellos que se centran en el análisis textual, es decir, aquellos que se enfocan en los mecanismos lingüísticos o literarios que permiten crear la ilusión de espacio en la narración; 2) aquellos que plantean posibilidades de interpretación de dichos espacios y lugares sin detenerse a mostrar los parámetros bajo los que estos se crean o pueden ser identificados. Los primeros podrían ser agrupados en una categoría centrada en "aproximaciones textuales" ${ }^{6}$ mientras que, los segundos, por su carácter interpretativo, podrían ser considerados de "aproximaciones fenomenológicas"?

\footnotetext{
${ }^{5}$ Publicado hasta 1975.

${ }^{6}$ Sin perder de vista que las "aproximaciones textuales" parten de alguna manera también de un "carácter interpretativo".

${ }^{7}$ Cabe aclarar que ninguno de los acercamientos aquí contenidos se declara propiamente "fenomenológico", dicha denominación obedece aquí al cariz interpretativo de los mismos.
} 
Dentro de las aproximaciones textuales agrupamos trabajos sobre el espacio publicados por críticos literarios, profesores, literatos e investigadores enfocados en la representación del espacio en textos literarios. Algunos de ellos no se centran exclusivamente en el espacio, pero lo tocan de manera tangencial como uno de los elementos analizables de toda obra literaria ${ }^{8}$ - García Berrio, Bal, Zoran-. Otros, en cambio, se dedicarán a la determinación espacial de ciertas obras, periodos, movimientos o autores - Pimentel, Zubiaurre-.

Los trabajos del segundo rubro no proponen métodos de "rastreo" o detección de construcciones espaciales, sino formas de interpretar la presencia de personajes en los lugares representados en el texto literario y sus acciones. Incluimos aquí trabajos como los de Mijaíl M. Bajtín, Gastón Bachelard, Aníbal A. Biglieri o Karla Xiomara Luna Mariscal, entre otros. Todos ellos ponen atención en el espacio a partir de paradigmas extraliterarios de funcionamiento espacial más que de los mecanismos lingüísticos y/o literarios usados para construirlo, es decir, se centran en el posible significado o sentido del espacio representado en la obra ficcional.

Después de esta revisión coincidimos con Janusz Slawinski — quien hace una extensa revisión de los estudios literarios sobre el espacio- en que el único inconveniente de esta abundancia de aproximaciones consiste en la heterogénea mezcla de léxicos y conceptos provenientes de varias disciplinas que son agrupados de manera arbitraria bajo el concepto de espacio. Derivado de ese panorama, el investigador polaco propone una clasificación en siete categorías de acuerdo con el interés que anima los estudios del espacio que revisa. ${ }^{9}$

Antes que Slawinski, Michel de Certeau en La invención de lo cotidiano enlistaba una serie de trabajos que, reducida a "quedarse sólo con los estudios

\footnotetext{
${ }^{8}$ Cabe aclarar que García Berrio, Genette y Bal desde enfoques narratológicos, plantean una meticulosa disección de la obra literaria en sus distintos componentes, el espacio entre ellos, esto es, no se centran en el análisis del espacio en particular.

${ }^{9}$ De manera breve las presentamos aquí aunque en la bibliografía consignamos la referencia completa al trabajo de este investigador: 1) los estudios del espacio entendido como "poética sistemática"; 2) los que lo consideran una "poética histórica"; 3) "las investigaciones sobre las representaciones espaciales fijadas en el sistema semántico del lenguaje y sus movilizaciones y 'prolongaciones' literarias" (268); 4) los que se centran en "poéticas o narrativas de los patrones culturales"; 5) aquellos que buscan "los universales espaciales arquetípicos, su papel en la formación de la imaginación de los escritores y sus exteriorizaciones en la estilística, la semántica y la temática de las obras" $(270) ; 6)$ los "concernientes a la naturaleza y forma del espacio literario concebido como copia analogon del espacio físico" (270); y, finalmente, 7) los textos que se encargan del estudio del espacio de las obras literarias en cuestión de estructura.
} 
relativos a las operaciones espacializantes (y no a los sistemas espaciales)" (128, las cursivas son del original), incluía

los que se refieren a una semántica del espacio (como los de John Lyons sobre los "Locative Subjects" y las "Spatial Expressions"), a una psicolingüística de la percepción (los de Miller y Johnson-Laird sobre "la hipótesis de localización”), a una sociolingüística de las descripciones de lugares (por ejemplo William Labov), a una fenomenología de los comportamientos organizadores de "territorios" (por ejemplo, Albert Escheflen y Norman Aschcraft), a una "etnometodología” de los signos de localización en la conversación (por ejemplo, Emanuel A. Schegloff), o a una semiótica que examina la cultura como un metalenguaje espacial (por ejemplo, la Escuela de Tartu, sobre todo Y. M. Loman, B. A. Ouspenski), etcétera (128).

Más recientemente y también con el ánimo de organizar el panorama espacio-literario, Alejandro Palma Castro et al han propuesto otro ordenamiento bajo el neologismo topoiesis. El término "define esos espacios, siempre vinculados a un tiempo, que se generan en y alrededor de la creación de un texto que representa una modelización de mundo" ("Topoiesis", 7). Bajo esta óptica se considera al hecho literario como acto comunicativo codificado de manera específica por un enunciador para un receptor, por lo que se pueden distinguir distintos niveles "espaciales": el espacio material del texto, el espacio de enunciación del mismo, el espacio representado en el texto como "escenario" de la narración y el espacio de recepción del texto. ${ }^{10}$

\footnotetext{
${ }^{10}$ Se ofrece, para cada uno, una categoría que permite su abordaje: 1) Topoiesis de los dispositivos de registro, que se encarga de revisar los estudios enfocados en el espacio "físico" del texto, centrando la atención en lo que Genette llamaría paratextos o en concepciones como la "zona visuográfica" de Viviana Cárdenas; 2) Topoiesis de las instancias de enunciación que se encarga de preguntarse por los mecanismos de enunciación y el espacio desde el que sucede el acto enunciativo; 3) Topoiesis de recepción, la cual se encarga de hacer notar la presencia de ciertos espacios donde se recibe y decodifica el texto literario y finalmente; 4) Topoiesis del espacio textual, que se preocupa de las representaciones espaciales dentro de la narrativa, es decir, la que se enfoca en los lugares en que ocurre la narración o que son mencionados en ella con alguna repercusión (o no) en el desarrollo de la misma y; 5) Topoiesis de recepción, vinculada a los espacios de lectura o recepción literaria.
} 


\section{APROXIMACIONES AL ESTUDIO DEL ESPACIO MEDIEVAL}

En cuanto a literatura medieval se refiere, son muchos los trabajos dedicados al estudio del espacio, sin embargo, nos vemos limitados aquí a mencionar sólo algunos. Entre ellos, el de Simone Pinet sobre el Poema de Mio Cid resulta interesante porque vincula el pensamiento de Michel de Certeau y Henri Lefebvre - de tipo más bien sociológico - a un texto literario, centrándose en la importancia del itinerario del Poema como válido para los fines del mismo, más allá de su exactitud histórica y geográfica, a la que siempre se ha hecho alusión. Pinet apunta que "la producción de un espacio en una época es resultado no sólo de las condiciones de 'realidad' que lo producen - trabajo, sociedad, política - sino de las condiciones de 'ficción' que lo integran, no produciendo un espacio alterno, sino por encima de y dentro del espacio general" ("Para leer", 199-200).

Otro artículo de obligada mención es el de Aníbal A. Biglieri que resulta útil no sólo para un corpus de obras medievales sino para el del espacio en la literatura en general aunque su enfoque sea específicamente medieval. En "Espacios narrativos medievales: propuestas para su estudio", Biglieri reflexiona sobre la construcción del espacio en el que ocurre una narración y propone cinco pautas a considerar para su estudio. Sus consideraciones, de manera resumida, son las siguientes: a) la literatura medieval no carece de alusiones espaciales, como generalmente se piensa, sino que estas son expresadas a través de recursos literarios, que en muchas ocasiones han sido consignados como propios de literaturas posteriores; b) el tiempo es un elemento sine qua non de la narración y puede ser más evidente que el espacio; c) el espacio presente en la literatura está mediatizado por el lenguaje, de manera que el primero resulta en un "constructo verbal"; d) no hay ni espacios ni lugares que no estén impregnados de valores positivos o negativos que reflejen "una visión del mundo" y que no requieran de la cooperación del lector; y e) los personajes tienen diferentes maneras de experimentar el espacio en el que se encuentran.

Por su parte, Karla Xiomara Luna Mariscal se ocupa del asunto en su libro El Baladro del Sabio Merlín. La percepción espacial en una novela de caballerías hispánica. Destacable resulta el hecho de que en esta propuesta se hable de "percepción espacial" en lugar de espacio. Si bien como el título lo indica, el estudio se enfoca en El Baladro del Sabio Merlín, Luna Mariscal dedica el segundo capítulo del libro a dar un panorama del espacio en la Edad Media, entendiendo este como "ámbito de vida y de imaginación humana, como 'territorio' donde el hombre vive la cálida costumbre de los espacios cotidianos 
o sueña su destino en el imaginario más allá” (La percepción, 53). Luna Mariscal, centrada en los siglos que van del XI al XIV, clasifica los espacios en tres grandes grupos: 1) espacios medievales —naturaleza, cosmografía, partes del mundo, monstruos, viajes y maravillas, y el paraíso terrenal-; 2) descubrimientos, relatos de viajes y geografía imaginaria; y 3) el más allá —el cielo-.

Para hacer su análisis de El Baladro del sabio Merlín, Luna Mariscal separa el texto en dos niveles: el de la fábula y el de la intriga. En cada uno desarrolla categorías de análisis vinculadas al espacio. ${ }^{11}$ En una de ellas, "Tópicos espaciales presentes en la obra”, esta autora se enfoca en los lugares presentes en la obra en cuestión, enlistando y contextualizando algunos de los más relevantes: la corte, el palacio — con sus salas, ventanas, corrales, cámaras y torres-, la ciudad, la iglesia, el bosque, el lago, la fuente y la montaña. Luna Mariscal muestra el papel de cada uno de estos lugares dentro de la narración al referir lo que en ellos acontece y su repercusión.

Alejandro Velázquez Elizalde, percibiendo la importancia que el espacio tiene, no sólo dentro de la narración, sino para la caracterización y desarrollo del caballero, estudia el espacio en Tirant lo Blanch. Su trabajo, dividido en dos artículos ("Ciudades, plazas" y "Aposentos privados, salas de consejo"), parte de la premisa de que ciertas características de dicha obra resultan atípicas dentro de la literatura caballeresca y esto se puede explicar a partir de los lugares en los que se mueve el caballero. Velázquez Elizalde organiza su estudio a partir del eje exterior/interior, ${ }^{12}$ distinguiendo para el primer caso, entre ciudades, plazas, posadas e iglesias, y en el segundo, lugares vinculados a la corte: aposentos privados, salas de consejo, huertos y otros lugares públicos de palacio. Coincidimos con Velázquez Elizalde cuando afirma que

si se considera que los espacios en los que se desarrolla la acción condicionan el desarrollo del héroe y, consecuentemente, su caracterización, entonces un estudio de los espacios en Tirant lo Blanch permitirá observar aquellos rasgos que dan cuenta de un cambio de visión del mundo, así como de un ideal didáctico expuesto mediante un nuevo tipo de caballero $(\mathrm{s} / \mathrm{p})$.

${ }^{11}$ En el primer nivel, el de la fábula, propone cinco grupos: el espacio como estructura; los tópicos espaciales presentes en la obra; modelos de horizontalidad e itinerancia; apertura y descubrimiento; y carácter ilimitado e imprevisible. En el segundo caso, el de la intriga, señala sólo dos: los niveles discursivos de la construcción espacial y la descripción.

12 De hecho, siguiendo ese orden publica dos artículos consecutivos en la revista Tirant, el primero está dedicado al espacio externo y el segundo al interior. 
No obstante, se podría agregar que la opción inversa es también plausible; esto es, que las características del héroe tuvieran repercusión en los lugares por los que este deambula.

\section{ESPACIALIDAD ${ }^{13}$ MEDIEVAL}

Para la geografía humana, ciencia que vincula las relaciones entre el ser humano y el entorno que lo rodea, el espacio es un concepto abstracto, de ahí que se prefiera hablar de lugares, es decir, formas concretas de espacio. Michel de Certeau, por ejemplo, considera que "un lugar es el orden (cualquiera que sea) según el cual los elementos se distribuyen en relaciones de coexistencia" (La invención, 129) mientras que "el espacio es un cruzamiento de movilidades. Está de alguna manera animado por el conjunto de movimientos que ahí se despliegan” (La invención, 129). Esto nos lleva a una primera distinción: a pesar de la cercanía de ambos términos, estos no son idénticos y su deslinde no siempre es claro. ${ }^{14} \mathrm{Si}$ el espacio, como decíamos al principio ha cambiado —en su definición, etc. - lo conducente sería que para su estudio se planteara primero lo que la época en cuestión entiende por espacio.

"Space carried meanings" advierte Barbara Hanawalt en la introducción a Medieval Practices of Spaces, libro dedicado al estudio y análisis del espacio medieval desde diferentes disciplinas. El espacio no ha dejado de significar, sin embargo aunque muchos de esos significados se han colado a través del tiempo hasta nuestros días, otros se han desvanecido. Cabe aclarar que la principal forma de reconstrucción de dicho pensamiento procede de los testimonios escritos de la época, que, es preciso recordar, funcionan bajo mecanismos distintos de los de la realidad, lo que aunque es bien sabido, para la Edad Media es doblemente cierto: las peculiaridades del sistema de copia y creación de textos, centrada sobre todo en el concepto de auctoritas, por un

13 En lo que se pudo cotejar para este trabajo, el término no parece ser usado como categoría de análisis. Simone Pinet, en "Para leer", menciona una "espacialidad" al referirse a los desplazamientos presentes en narraciones que siguen una cierta retórica como los textos que hablan de viajes o paseos, pero no lo usa para reemplazar el término espacio, como sí se propone aquí.

14 Por ejemplo, aunque la mayoría de los geógrafos o sociólogos que estudian el espacio distinguen al lugar como componente del espacio, para De Certeau sucede lo contrario. Cresswell señala: "Confusingly for geographers de Certeau uses space and place in a way that stands the normal distinction on its head. To de Certeau place is the empty grid over which practice occurs while space is what is created by practice" (Place, 1916).

Medievalia 52:2, 2020, pp. 131-155 
lado, busca siempre la referencia fiable; y por otro, permite la fácil manipulación del contenido textual de dicha autoridad. ${ }^{15}$

Esta circunstancia no desautoriza los textos, simplemente los muestra dentro de su contexto original para permitirnos ser cautos, entendiendo que se nos presentan como manifestación autónoma de la realidad — aunque no desvinculada por completo- - Se debe, por tanto, entender que los textos escritos forman parte de un corpus escriturario que funciona, como muchos otros, paralelo a la realidad a la que se parece y da forma, pero de la cual es independiente. ${ }^{16}$ Así pues, no esperemos encontrar en estos textos una necesaria coincidencia con la realidad empírica y objetivable, si bien tampoco nos encontramos frente a textos arbitrarios y sin sentido de la representación, sino a una mentalidad propia de su contexto particular.

140 Nos parece que la relación entre una sociedad y su organización del espacio es el resultado de procesos sociales más bien complejos. Para Guerreau, "la civilización medieval disponía de un sistema de representación del espacio totalmente original, que seguramente era el eje principal de todo el sistema de representaciones de esa sociedad" ("El significado", 182). No se puede, además, olvidar el papel primordial que en dichas representaciones jugó la Iglesia, que, para el momento, se encontraba posicionada en la cima de la pirámide social y era la gran monopolizadora tanto de los conocimientos como de sus medios de transmisión. Bien mirada, esta organización, ya muestra una orientación espacial en donde se marca una jerarquía que establece un arriba y un abajo en los estamentos sociales que impregnarán todos los ámbitos de la vida. ${ }^{17}$ Para Johan Huizinga, "el hombre medieval piensa dentro de la vida

${ }^{15}$ Biglieri apunta que "en este tipo de sociedad predomina una "tendencia a la inmovilidad", a "conservar y transmitir lo sabido" según una "concepción tradicional estática del saber", que lo define como "un contenido dado que se transmite". De allí la enorme influencia que ejercen las auctoritates y la constante remisión a las fuentes clásicas como repositorios de un saber establecido que, más que renovar, hay que transmitir a la posteridad. Dos fuerzas en pugna se hallan así en la base de la textualidad medieval: el respeto reverencial por la autoridad de los predecesores y las libertades que, pese a todo, se tomaban sus continuadores frente al códice que leían, copiaban y comentaban” (Ideas, 32).

${ }^{16}$ Coincidimos con Alejandro Higashi cuando, a propósito de las imágenes arquetípicas de algunos caballeros medievales, afirma que estos textos tienen una lógica propia "cimentada en un cruce muy rico de propósitos y presupuestos, de estilos retóricos y tradiciones literarias, lógica que al final nos habla más de las tensiones a las que estuvieron sujetos los autores y su público que propiamente de una realidad objetiva" ("Algunos arquetipos", 35).

${ }^{17}$ Para Guerreau, por ejemplo, este modelo de organización social refleja una perspectiva espacial que involucra "varios niveles de realidades" ("El significado", 183) donde se impone una jerarquización que se aleja de la organización romana preocupada por la equidad y la justicia de la civitas. 
diaria en las mismas formas que dentro de su teología. La base es en una y otra esfera el idealismo arquitectónico que la escolástica llama realismo: la necesidad de aislar cada conocimiento y de prestarle como entidad especial una forma propia, de conectarlo con otros en asociaciones jerárquicas" (El otoño, 325). Debemos entonces comprender que la ligazón entre el pensamiento religioso y la vida cotidiana hace de la configuración de los espacios una simbiosis orgánica de muchos de los aspectos de la vida medieval.

Entre algunos de los estudios enfocados en esta mentalidad medieval del espacio encontramos, por ejemplo, a Michael Camille, quien usa el término en plural y habla de espacios y no de "espacio" porque afirma que, "the word 'espace' meant an interval of time or distance $[. .$.$] and not our modern$ abstract notion of space, which is a postemedieval category" ("Signs of the City”, 9). También Jérôme Baschet nos previene de usar el término indiscriminadamente pues "en la Edad Media se ignora este concepto, al menos en el sentido que nosotros lo entendemos, a saber, como espacio continuo y homogéneo, infinito y absoluto" (La civilización feudal, 364). Esta circunstancia, según Baschet impulsa el uso del término lugar. ${ }^{18}$ Estos lugares, continúa el francés, sufrieron diversos procesos de configuración y transformación, como el "encelulamiento".

Paul Zumthor, por su parte, en La medida del mundo se sirve del cuerpo humano que recorre el espacio para organizarlo en muchas y diferentes categorías como el terruño, la ciudad o el universo. Para el suizo, "el espacio medieval no es ni abstracto ni homogéneo. En nuestra jerga publicitaria, diríamos que está 'personalizado': concreto, individual, heterogéneo, pero íntimo. No se concibe como un medio neutro, sino como una fuerza que rige la vida, la abarca, la determina ... la fascina" (La medida, 36). A partir de esta corporalidad, Zumthor establece la relación con los otros, de donde surgirá el "espacio social” que llevará a la elaboración de ideas, conceptos y mitos sobre el espacio. ${ }^{19}$ Harald Kleinschmidt en Comprender la Edad Media, distingue tres esferas de experimentación del espacio medieval: el espacio de la experiencia

\footnotetext{
${ }^{18}$ Según Baschet el término lugar se distinguía del de "espacio" pues el primero "se define como aquello que contiene las cosas que en él se encuentran" (La civilización feudal, 364), mientras que el segundo "designa principalmente el intervalo entre dos objetos" (La civilización feudal, 364).

${ }^{19}$ Zumthor organiza su estudio en torno a tres rubros: "las imágenes conceptuales o figurativas que operan a través del lenguaje o de las artes miméticas" (La medida, 18); lo que él llama esquemas, modelos o tipos; y el de los arquetipos entendiendo estos como una "huella de la memoria aislada, depurada, reducida a un brote imaginativo de experiencias antiquísimas" (La medida, 18).
} 
cotidiana, el espacio de la comunicación regular y el mundo. El primero "representa el lado íntimo de la vida de una persona, y el círculo íntimo de actividades de las personas en los grupos, la finca, la casa o la habitación. El espacio de la experiencia cotidiana es un espacio privado en el sentido de que uno lo contempla desde dentro y cree que es su único dueño" (Comprender, 46). El espacio de la comunicación humana consiste en aquel "donde uno se encuentra con los demás, con forasteros, amigos, extranjeros o enemigos. El espacio de la comunicación regular es público en el sentido de que no es propiedad exclusiva de una persona o grupo, sino que puede ser utilizado por otros" (Comprender, 47). Estas dos últimas categorías comparten la característica de ser experimentables a partir de las acciones de las personas que los habitan. El mundo, como categoría espacial, en cambio, "puede ser conocido por las 142 personas y grupos de la tierra únicamente mediante la reflexión teórica, y no a través de cualquier acción distinta al pensamiento" (Comprender, 48). En esta división se percibe la importancia de la relación interpersonal ya sea entre los miembros de un mismo grupo o de uno diferente, de manera que el tipo de interacción es el que determina los espacios.

En cuanto a la etimología del término en lenguas occidentales, cito in extenso a Zumthor pues el recorrido que traza de los términos spatium y locus, resultará crucial para una mejor comprensión:

Todas las lenguas románicas heredaron del latín locus o (como el español y el portugués) de algunos de sus derivados: los términos que provienen de esta raíz designan el emplazamiento en el que se encuentra un objeto determinado. El germánico rum, raíz del alemán raum, del neerlandés ruimte y del inglés room, tuvo en su origen el mismo sentido, que se conservó en estos idiomas hasta la época premoderna. El francés, por su parte, sacó del latín popular platea la palabra place para significar (como el alemán statt, el inglés antiguo stede, el islandés stadhur) el lugar mismo en el que se está; el inglés y el neerlandés lo tomaron para darle el sentido general de locus. Spatium, sin embargo, no parece haber entrado en el uso general: palabra culta, que solo pasó al francés (de donde lo tomaron posteriormente otros idiomas), donde designó hasta los siglos XVI o XVII un intervalo cronológico o topográfico que separa dos puntos de referencia. La expresión sans espace, que empezamos a encontrar hacia 1175, tiene significado común de 'inmediatamente' (La medida, 51).

En castellano, por su parte, encontramos que el Vocabulario de Nebrija de 1495 hace la distinción entre "espacio de tiempo o lugar" y "espacio este mesmo como intervallum", mientras que bajo la entrada de "lugar" apunta 
"lugar en que está alguna cosa, locus", "lugar en que algo se recibe, conceptaculum", "lugar en esta manera, receptaculum", "lugar donde algo se guarda, repositorium", "lugar adonde huimos, refugium", "lugar este mesmo, profugium, confugium" y "lugar donde juzgan, fórum" (Vocabulario, 124). De lo anterior puede concluirse por lo menos dos cosas importantes. La primera es que la definición de espacio está vinculada al tiempo; y la segunda es que la idea de espacio es menos específica que la de lugar, pues esta última se refiere al menos a cinco tipos mientras que la primera sólo a dos. Espacio y lugar tampoco fueron sinónimos para la Edad Media, sino términos próximos, pero distinguibles. Estas concepciones de tiempos y espacios cíclicos y finitos es la que se percibe en los textos medievales y de las que se tendría que dar cabal cuenta en sus análisis. ${ }^{20}$

Concluimos pues que la gente de la Edad Media habitaba lugares, no espacios. Se considera al lugar como espacio humanizado, es decir, aquel del que el ser humano se ha apropiado a través de diversos procesos. ${ }^{21}$ Es en esos lugares - a veces con nombre y "apellido"-, donde sucede el cotidiano quehacer humano, ya sea en el mundo referencial o en el de ficción.

Estos lugares son percibidos por una presencia física que desde su existencia particular da cuenta de lo que le rodea; de ahí el uso del término "espacialidad", 22 entendida esta como la serie de coordenadas y relaciones

${ }^{20}$ En "La cicatriz de Ulises", por ejemplo, Erich Auerbach nos previene de mirar textos tan alejados a nosotros con ojos contemporáneos. Auerbach lo muestra con las descripciones y digresiones homéricas: "lo primero que se le ocurre pensar al lector moderno es que con este procedimiento se intenta agudizar aún más su interés, lo cual es una idea, si no completamente falsa, al menos insignificante para la explicación del estilo homérico" ("La cicatriz de Ulises”, 10). Este análisis de Auerbach deja ver que los textos literarios — de cualquier épo$\mathrm{ca}$ - recurren a aquellos elementos lingüísticos y literarios que le son útiles y/o necesarios para sus propósitos; lo que refuerza nuestra propuesta de ir más allá de la descripción cuando de espacialidad se trata.

${ }^{21}$ A este respecto puede revisarse Place and Politics de John Agnew, Place. A Short Introduction de Tim Cresswell que, entre otros autores, se centran en la definición de ambos términos. Ambos establecen por lo menos tres fases del proceso de apropiación: localización, locación y sentido de lugar (location, locale y sense of place en los originales, la traducción de los términos es propia).

${ }^{22}$ Heidegger, en Ser y tiempo, define la espacialidad como condición sine qua non del Dasein. Para el filósofo alemán, el espacio es "algo constituyente del mundo, ya caracterizado a su vez como un elemento estructural del 'ser en el mundo"' (Ser y tiempo, 116) mientras que la espacialidad, "está fundada en la mundanidad del mundo" (Ser y tiempo, 116), de lo cual se puede concluir que el espacio será una atribución del mundo mientras que la espacialidad lo será del ser. El espacio, siguiendo a Heidegger, es una concepción abierta que tiene que ver con el "ser ahí" en la medida en que lo contiene, y la espacialidad, por su parte, es una cualidad del "ser ahí"

Medievalia 52:2, 2020, pp. 131-155 
espaciotemporales, sociales, culturales, etcétera, percibidas y verbalizadas por el ser humano. Entenderemos entonces que el estudio de la espacialidad en la obra literaria involucre a los lugares presentes en la misma y a la serie de relaciones entre, por ejemplo, narradores, objetos, personajes, percepciones, descripciones y acciones realizadas, incluyendo los desplazamientos.

Esta preferencia hacia el término espacialidad se ve reforzada por la revisión hecha a una gran cantidad de trabajos literarios sobre, o vinculados al estudio del espacio — no sólo, pero sobre todo- en el ámbito literario. De dicha labor se concluyó que la disparidad en su acercamiento y la falta de una definición o consenso terminológico complican su sistematización en una obra literaria: más que lugares en sí, lo que las obras literarias presentan a sus lectores son percepciones y valoraciones de los lugares en que sucede lo que se narra, lugares que, sin esa presencia humana, resultan bastante carentes de sentido. Consideraciones como alto o bajo, grande o pequeño, frío o caliente, no son más que maneras de verbalizar una experiencia física y en esto, la literatura no se aleja de la "realidad", de manera que utiliza mecanismos lingüísticos y literarios en la recreación de los mundos intraliterarios a semejanza de los extraliterarios.

El estudio de la espacialidad entonces dista mucho de ser una enumeración centrada en los lugares presentes en la narración; se trata más bien de considerar las posibilidades particulares de análisis de los mismos a partir de los mecanismos verbales — lingüísticos y/o literarios - predominantes en el texto y de las relaciones que estos tengan con otros elementos como los personajes. Habrá obras literarias en las que la espacialidad se manifieste principalmente a través de la descripción, habrá otras en las que se recurra a los desplazamientos, y las habrá que intenten obviarla al no hacerla explícita. No obstante, el lugar o lugares en los que suceden las historias predisponen una serie de relaciones entre los personajes; el desarrollo de lo que con ellos sucede y viceversa. Estos lugares son producto de la experiencia y experimentación humana del espacio. Como consecuencia de lo anterior, se puede inferir que la espacialidad de la obra literaria no es ni casual ni neutral para la acción de la narración: el bosque, la ciudad, una habitación tienen una carga ideológica y simbólica que no puede ser obviada.

Esto es constatable a partir de la selección de lugares en los que ocurre la narración, lo que en ellos ocurre, los personajes que en ellos concurren y

que se rige a partir del des-alejamiento y la dirección. Estas consideraciones fundamentan la decisión de hablar de espacialidad en vez de espacio, pues vinculan estrechamente el espacio al ser humano como aquello que lo contiene y que es parte de su realidad circundante. 
sus vínculos. Así, un análisis comprehensivo debería considerar, por lo menos dos fases complementarias: a) una de identificación de los mecanismos de construcción de la espacialidad: elementos literarios, lingüísticos y/o narrativos que la conforman, y b) otra en la que a través de la relación entre los personajes, sus acciones y los lugares se pueda percibir el papel que estos últimos desempeñan en una narración. A lo primero se le ha denominado aquí "gramática de la espacialidad" mientras que lo segundo sería una "semántica de la espacialidad” que, además de determinar el valor concedido a un lugar específico en una obra, la ponga en contacto con otras espacialidades de la misma obra o bien de otras obras o de realidades extraliterarias, artísticas o empíricas. Debe quedar claro que estamos considerando al texto como un todo que se manifiesta en dos realidades, la verbal y la de los significados, de manera que no se debería estudiar uno sin aludir a la otra, es decir, lo que aquí se propone son dos momentos de un mismo proceso y no dos partes aisladas e independientes. La distinción propuesta tiene un objetivo meramente práctico: partir de la obra para, posteriormente contextualizar la espacialidad presente a partir de la historia que se cuenta, sus actores y las acciones de estos, todos como elementos constituyentes de dicha espacialidad.

\section{GRAMÁtiCA DE LA ESPACIALIDAD}

Esta gramática tendría como tarea central desentrañar los elementos que intervienen en la conformación de los lugares presentes en la obra literaria. Para un corpus medieval, se propone considerar, entre otros, estos aspectos: las instancias enunciativas ${ }^{23}$, la toponimia — en el caso de que la hubiera-, las descripciones, ${ }^{24}$ los personajes y sus acciones y los lugares en sí.

\footnotetext{
${ }^{23}$ Según la topoiesis de las instancias enunciativas, en toda comunicación literaria se puede distinguir entre locutor (autor), enunciador (narrador), alocutario (narratario) y lector. De su interacción se desprenden dos estadios narrativos: la situación de comunicación y el esquema de enunciación. El primero tendrá que ver con las decisiones extratextuales que el locutor tomará para dar forma a su enunciación, tales como repertorio literario, ideología o lugar de publicación. El segundo opera al interior del texto y se centra en el narrador como punto de partida: "la topoiesis del esquema de enunciación deberá comenzar por situar al enunciador en su lugar para de ahí determinar el significado que produce" (Escobar et al., "Topoiesis de las instancias enunciativas", 33). La propuesta, no obstante, no ahonda en lo que significa "situar" al narrador o en cómo hacerlo.

${ }^{24}$ Como se podrá notar, la descripción es otro de los elementos susceptibles de análisis, pero no el único ni el principal.
} 
Las instancias enunciativas, es decir, narrador o narradores, son relevantes ya que, en gran medida, son el primer acercamiento a la diégesis. Sumariamente se podría señalar que su análisis debería considerar por lo menos tres cosas: 1) la caracterización de dichas instancias, 2) su función dentro de la obra literaria, y 3) los lugares desde donde y sobre los cuales se pronuncia.

La caracterización tiene que ver con el componente corporal o material que da acceso a la voz narrativa al conocimiento de los lugares. Para Fernando Ainsa, la presencia humana es insoslayable tanto en la percepción, como en la representación del espacio en la obra literaria:

La intencionalidad del sujeto define, pues, la objetividad de las cosas y toda descripción del espacio, incluso en las proyecciones cartográficas, atenidas a reglas codificadas como planos, mapas y planisferios, no son otra cosa que el resultado de las convenciones por las cuales el médium se disimula entre el objeto y la representación científica ("Del espacio vivido”, 24).

$\mathrm{El} / \mathrm{la}$ narrador/a, como recurso enunciativo, es en principio quien se encarga de guiar nuestro recorrido literario. Este/a narrador/a — como personaje o mero testigo - tendrá una perspectiva respecto de la historia que cuenta y tanto su caracterización como su papel en la narración tendrán una repercusión en lo que se diga de los lugares y sus dimensiones. Esta perspectiva atenderá a cuestiones de edad, raza, género, estatus social, económico, ideológico, etcétera, que conformarán, por un lado, su experimentación de la espacialidad, y por otra los mecanismos verbales utilizados para dar cuenta de dicha experimentación. Esta caracterización implica "situar" al narrador.

El DLE define situar como "poner a alguien o algo en determinado sitio o situación” (en línea). Etimológicamente proviene del latín situs que era usado para denotar sitio o posición. Esto puede ser interpretado de dos maneras: desde la acepción puramente física de localización espaciotemporal y desde la relacionada a una postura o actitud desde la que se enuncia — tan importante la una como la otra-, de manera que para situar al enunciador, primeramente habrá que distinguir el modo, la voz y la perspectiva ${ }^{25}$ del mismo para reconocer y entender los mecanismos de enunciación y los valores otorgados a la espacialidad del texto. Así, un primer referente de espacialidad serán el narrador; sus distancias, miradas, consideraciones, etcétera, expresadas

${ }^{25}$ Términos tratados todos por Genette en Figuras III y en Nouveau discours du récit, textos a los que hacemos referencia en la bibliografía y a los que remitimos al lector interesado mencionando, no obstante, que su inclusión en nuestra propuesta radica en los parámetros de cercanía o distancia de esta instancia con respecto a la historia que narra y sus lugares. 
verbalmente a través de diferentes recursos literarios y/o lingüísticos: lexemas nominales, deícticos, descripciones, metáforas, entre otros.

\section{Toponimia}

En cuanto al nombre del lugar es importante señalar su función particularizante: el nombre que se le da a un lugar, ciudad, pueblo, edificio, etcétera, tendrá que ver con sus características orográficas, históricas, simbólicas, por lo que puede resultar relevante. Cabe recordar que, como ya se mencionaba, el acto de nombrar un lugar es parte del proceso de apropiación humana del espacio y una de las distinciones más importantes entre espacio y lugar. ${ }^{26}$

Aunque la toponimia se refiere exclusivamente al uso de nombres propios, la ausencia de estos también puede ser harto relevante: la forma de referirse a un lugar puede decir más de quien habla que del lugar en sí. Hay que considerar que los nombres propios están cargados de una serie de connotaciones que particularizan la ciudad, el bosque, la calle, etcétera. Fuente Ovejuna no es un pueblo cualquiera, la isla de Tule no es sólo una isla situada al norte, Jerusalén es Tierra Santa. La referencialidad del lugar en cuestión puede ser relevante o no, dependerá por un lado de lo que ahí ocurra y de los personajes que intervengan, lo importante es que el hecho de tener un nombre por derecho propio contribuye a hacer ese lugar único, ${ }^{27}$ lo llena de características en el imaginario colectivo.

Si se habla de un lugar con referente extraliterario — las Indias, de donde proviene la estirpe del caballero Çifar, por ejemplo — no se trata de contrastar las características de uno y otro, sino de considerar que a pesar de la independencia de ambos, la referencia no resultará casual. En el caso de Çifar que se acaba de mencionar, para Campos García Rojas, Asia sirve para hacer aparecer al héroe como exótico y cercano al Jardín del Edén ("Pre-history", 4) ${ }^{28}$

\footnotetext{
${ }^{26} \mathrm{Al}$ respecto puede consultarse el clásico de John Agnew, Place and Politics, o los trabajos de Tim Cresswell o Yi Fu Tuan consignados en la lista de referencias de este trabajo y que comparten la idea de que una de las formas de apropiación del espacio es darle un nombre.

${ }^{27}$ Existen, no obstante, muchos lugares del continente americano que fueron nombrados en referencia a otros ya existentes en Europa: Salamanca, Mérida, Córdoba, y en cuyo nombramiento opera un intento "civilizador" de doble orientación: hacia el pasado y la referencia conocida, y hacia el futuro y las posibilidades de mejora. A estas habría que agregar aquellos lugares a los que antepuso "nuevo/a" como en Nueva Granada, Nueva España, Nuevo León, etc. y en el territorio actual de Estados Unidos, nombres de ciudades, estados o regiones, como New York, New Amsterdam, New Jersey, New England, New Hampshire, etc.

${ }^{28}$ Además, en la opinión del mismo Campos García Rojas: "People in the Middle Ages knew of India's existence and used its name as common referent for remote places. Although
} 
Habrá que considerar asimismo que tanto los lugares "naturales" como los "hechos" por manos humanas pueden ser nombrados a partir de sus características físicas, sucesos históricos, leyendas o personajes que los habitan — como por ejemplo el lago del relato de la Dama del lago_-; de ahí que los personajes sean importantes para el análisis y significación de la espacialidad medieval.

\section{Personajes}

Los personajes, por otro lado, al ser parte de la historia que se narra tendrán su propia experiencia de la espacialidad que puede ser coincidente o no con la del narrador y enriquecerla. Esa "voz narrativa” o instancia enunciativa, es, 148 generalmente, sólo una de las voces de la historia, en muchos casos ni siquiera corresponde a la del o la protagonista, por lo que, lo que los demás personajes digan o perciban de un lugar determinado —o de lo que en él hagan- permitirá tener una perspectiva más amplia, no sólo del lugar sino de su sentido dentro de la obra y por ende de lo que este representaba en el imaginario del momento.

En mayor medida que las instancias enunciativas, los personajes están dotados de una corporeidad ${ }^{29}$ — humana o no- que les permite percibir sus alrededores y los lugares por donde deambulan o aquellos que ven. Esta percepción, coincidente o no con la del narrador, muestra una "situación" distinta frente al lugar. Algunas de las características que se pueden tomar en cuenta, como en el caso de las instancias enunciativas serán, género, edad, estatus social o económico, entre otros.

La individualidad e identidad de los personajes resulta importante así como el nombre y los atributos que permiten reconocerlos como individuos; ${ }^{30}$ parece claro que hombres, mujeres, nobles, plebeyos, niños, adultos, cristianos, musulmanes, etc., tienen maneras diferentes de experimentar un

India and Asia appeared on medieval maps and in the books of travelers, the familiar way in which they are mentioned does not imply that the speaker was certain of what was to be found there" ("Pre-history", 4).

${ }^{29}$ Se habla de la corporeidad de los personajes ya que, en ocasiones, estos pueden ser fuerzas de la naturaleza u otros elementos antropomorfizados, como el conocido tópico medieval de don Carnal y doña Cuaresma en los que ambos son representados como hombre y mujer respectivamente.

${ }^{30}$ Para Pimentel en El relato en perspectiva destaca además el hecho de que el nombre de un personaje sea referenciable y añade a eso rasgos y atributos de cada uno que serán verbalizados a través de procesos como repetición, acumulación y transformación. 
mismo lugar: la caverna que sirve de refugio al ermitaño puede ser un lugar tenebroso para un niño perdido; el lugar sigue siendo el mismo, pero el horizonte de percepción y experimentación de cada uno están en consonancia con la situación de la que se hablaba antes. ${ }^{31}$

Incluir la perspectiva de los personajes en este análisis tiene varios objetivos. Si, como se viene diciendo no hay espacios neutros, la presencia o ausencia de los personajes en ciertos lugares puede ser un indicio de la configuración de estos últimos en la obra literaria, cosa que puede obedecer a fines exclusivamente narrativos o literarios o a una postura ideológica política, histórica, etcétera. La perspectiva particular de los personajes respecto a los lugares puede obedecer a cuestiones estilísticas, narrativas o extraliterarias, como convenciones sociales en cuanto a su género o profesión.

Acciones

Los lugares son, en gran medida, resultado de sus usos y funciones en el acontecer humano, o sea, de las actividades que en ellos se realizan. Una escuela, un templo, un parque, fueron concebidos desde su génesis con un objetivo particular en mente. Sin embargo no todos los lugares son creados, los hay naturales, "dados" como parte de la geografía del planeta lo que no los exime de tener un uso o "función". Ríos, montañas, bosques, desiertos y otros accidentes de la orografía pueden llegar a tener mayor significado que los lugares o edificios construidos por la mano humana - los ríos, por ejemplo, "que salen del paraíso, también los hay que salen del Infierno como el Aqueronte o el Leteo" (Kappler, Monstruos, demonios, 35)-.

En cualquier caso, habrá que considerar toda la carga de simbolismo que, bajo premisas de convención social establecen, delimitan, regulan no sólo su forma y dimensiones físicas, sino también y más importante, sus actividades, horarios, vestimenta, etcétera. Habrá lugares con más restricciones que otros, dependiendo de su función: iglesias, cárceles, cementerios, bibliotecas, entre otros, son ejemplos de lugares con claras pautas de acceso y comportamiento. Esta codificación contribuye a la clasificación de los lugares en públicos o privados, abiertos o cerrados, incluyentes o excluyentes, entre otras categorías de ordenamiento, como el "lecho" del padre del "Cuento del medio amigo" en donde este esconde el supuesto cadáver del enemigo de su hijo para que nadie lo descubra.

\footnotetext{
${ }^{31} \mathrm{Al}$ respecto puede verse el artículo de D. W. Meinig, “The Beholding Eye. Ten Versions of the Same Scene".
} 
A pesar de que se puede pensar en un repertorio bastante estable de lugares arquetípicos occidentales, convendría recordar que este es resultado de procesos sociales, históricos y culturales —entre otros - : los lugares, sus nombres, funciones y habitantes o visitantes se interrelacionan de manera intencional dentro de la obra literaria para presentar un modelo de mundo al lector que puede sustentarse en el extraliterario o, por el contrario, ser particular a la historia o a la obra en cuestión. Esto es lo que se propone como objeto de análisis de la semántica de la espacialidad: el sentido de las relaciones entre los elementos que conforman la gramática de la espacialidad recién propuesta.

\section{SEMÁNTICA DE LA ESPACIALIDAD}

Mientras que la gramática de la espacialidad pretende mostrar los elementos que pueden arrojar rasgos de espacialidad, la semántica se centra en establecer la serie de relaciones que entre ellos se puede establecer. Cabe aclarar que como propuesta particular para el estudio de la espacialidad en textos medievales - aunque no exclusivamente-, esta gramática busca mostrar las peculiaridades de la espacialidad de esos textos. Esta propuesta considera que hay, ineludiblemente, una presencia que percibe y desde esa percepción da cuenta del entorno circundante. Si esta gramática parte del texto para identificar una serie de recursos verbales y literarios que operan en la construcción de la espacialidad, la semántica irá más allá del texto para tratar de ampliar la lectura de dicha espacialidad contextualizándola. En muchos casos, tanto la gramática como la semántica se corresponderán con modelos enclavados en una estética o ideología establecidas. ${ }^{32}$ El reconocimiento de dicha filiación -o ausencia de la misma - no puede sino enriquecer la lectura y valoración de los textos. Por lo tanto, la semántica de la espacialidad tomará como base todos los elementos mencionados dentro de la gramática, especialmente los personajes - y las características de estos (género, edad, estamento social, etc.) — para ver cómo son percibidos y valorados los lugares en que se desenvuelven. Lo que se persigue es valorar los lugares presentes en la narración en relación con la tradición literaria a la que el texto corresponde para ver la contribución de dicho texto a la construcción del imaginario espacial intra y extraliterario. La habitación, por ejemplo, con toda su carga de intimidad puede servir de escenario para consumar el amor de dos amantes o como lugar de

32 Tenemos el ejemplo de las laudates civitatum y su retórica como género particular independiente de las características específicas de la ciudad a la que refieren. 
adoctrinamiento como en el caso del Libro del cavallero Çifar, que para "castigar" a sus recién recuperados hijos, se encierra en sus habitaciones.

Como vemos, los personajes o los lugares por sí solos no arrojan resultados comprehensivos, por lo que la semántica de la espacialidad debe establecer un diálogo entre algunas o todas las variables que se han venido señalando. Dado que el énfasis de este trabajo se encuentra en los lugares, estos serán el eje rector, lo que derivará en — por lo menos - tres categorías relacionales: 1) lugares-enunciador(es), 2) lugares-personajes y 3 ) lugares-lugares.

En cuanto a la primera categoría, lo que pretende es destacar las estrategias literarias, en especial las medievales, porque, al ser diferentes a las de otro tipo de literatura más cercana a nosotros, tienden a ser minimizadas. Dichas estrategias, no obstante, atienden a sus orígenes particulares, aunque pueda resultar arriesgado generalizar a este respecto por tratarse la Edad Media de un periodo muy extenso de tiempo (unos diez siglos), en un territorio bastante irregular en cuanto a su desarrollo.

La segunda categoría, la de los personajes, es relevante ya que son ellos los que deambulan por los lugares de la narración, llenándolos de significado, convirtiendo molinos en gigantes, como hiciera don Quijote. Se podría decir, por ejemplo, que son los personajes ilustres que encuentra Dante en el Infierno, el Purgatorio y el Paraíso los que complementan el sentido de cada lugar y viceversa, los personajes se ven limitados a las posibilidades de acción de estos lugares. ${ }^{33}$

Finalmente, la tercera categoría pone en relación los lugares dentro de la obra. Puede tratarse de dos lugares con la misma denominación —bosque, castillo, ciudad-, de manera que una ciudad se defina en contraposición a otra, o un bosque a otro bosque, por ejemplo; o diferente — bosque/ciudad-, en donde la oposición podría complementar los imaginarios que se tienen de cada lugar. Esto podría verse claramente en "Aquella cibdat ribera de la mar. La representación de las ciudades en El caballero Zifar" de María José Rodilla, quien distingue dos grandes grupos de ciudades: uno, formado por cuatro tipos de ciudades ${ }^{34}$ y otro que incluye "ciudades reales" (402) como Roma (contenida en el "Prólogo"), Babilonia y Nínive.

De la conjunción de estas tres categorías se desprende un panorama bastante comprehensivo del significado de los lugares para la época medieval,

${ }^{33}$ De acuerdo con lo que se ha venido planteando y salvando la discusión ontológica sobre el Inifierno, el Purgatorio y el Paraíso se piensa en ellos como lugares dado que la obra los plantea con una materialidad que les da dimensiones, olores, formas, etc.

${ }^{34} \mathrm{El}$ primero correspondiente a la imagen típica de la ciudad "amurallada, con calles estrechas y curvas que van a dar a un centro; de ella sobresale la verticalidad del castillo, y en 
su valor alegórico, la relevancia de su posesión o pérdida, el contraste entre espacio público y privado, la importancia de sus edificaciones, en pocas palabras, la conceptualización de esos lugares en el imaginario que resulta esencial, para una sociedad tan codificada como la medieval, sin olvidar, además, la gran repercusión de ese imaginario no sólo a nivel textual, sino también como modelo de mundo extraliterario.

\section{BIBLIOGRAFÍA}

Agnew, John, Place and Politics: The Geographical Mediation of State and Society, Boston y London: Allen and Unwin, 1987.

Ainsa, Fernando, "Del espacio vivido al espacio del texto. Significación histórica y literaria del estar en el mundo”, Anuario de Filosofía Argentina y Americana, 20, 2003, 19-36.

Auerbach, Erich, "La cicatriz de Ulises", en Mimesis. La representación de la realidad en la literatura occidental, México: Fondo de Cultura Económica, 1950, 9-30.

Bachelard, Gastón, La poética del espacio, Buenos Aires: Fondo de Cultura Económica, 1965.

Bajtín, Mijaíl M., "Las formas del tiempo y el cronotopo en la novela”, en Teoría y estética de la novela, Madrid: Taurus, 1989, 237-409.

BAL, Mieke, Teoría de la narrativa (una introducción a la narratología), Madrid: Cátedra, 1990.

BASChEt, JÉRÔMe, La civilización feudal. Europa del año mil a la colonización de América, México: Fondo de Cultura Económica, 2009.

Biglieri, ANíBAL A., "Espacios narrativos medievales: propuestas para su estudio", en Devid Paolini (ed.), "De ninguna cosa es alegre posesión sin compañía" Estudios celestinescos y medievales en honor del profesor Joseph Thomas Snow, New York: Hispanic Seminary of Medieval Studies, 2010, 24-37.

el exterior de la muralla, se extiende el campo siempre amenazante por el que llega la guerra" ("Aquella cibdat", 397) cuyo énfasis radica en la ciudad como campo de batalla. El segundo centra su atención en los ciudadanos y su modus vivendi: la agricultura y ganadería, actividades que conllevan desplazamientos entre el interior y el exterior de la ciudad. Un tercer tipo de ciudad es aquel que se sostiene de su actividad portuaria y que para el caso del Çifar resulta importante por la serie de encuentros y desencuentros entre los personajes. La cuarta y última categoría de ciudad del primer grupo lo constituyen las ciudades maravillosas: "la ciudad del lago de la historia del Caballero Atrevido" ("Aquella cibdat", 400), las Ynsulas Dotadas y "Monteçaelo, en el reino de Çafira" ("Aquella cibdat", 401). En estas tres el predominio de lo fantástico, lo maravilloso y exótico representa su característica principal. 
Biglieri, ANíbAl A., Las ideas geográficas y la imagen del mundo en la literatura española medieval, Madrid: Iberoamericana/Vervuert, 2012.

Blanchot, Maurice, El espacio literario, Madrid: Editora Nacional, 2002.

Camille, Michael, "Signs of the City. Place, Power, and Public Fantasy in Medieval Paris", en Barbara Hanawalt y Michael Kobialka (eds.), Medieval Practices of Space, Minneapolis y London: University of Minnesota Press, 2000, 1-36.

Campos García Rojas, Axayácatl, "Pre-history and Origins of the Hero in 'El libro del cavallero Zifar'and 'Amadís de Gaula”, Medievalia, 32-33, 2001, 1-10.

Certeau, Michel de, la invención de lo cotidiano. 1 Artes de hacer, México: Universidad Iberoamericana, Biblioteca Francisco Xavier Clavigero, Centro de Información Académica, 1996.

Cervantes, Miguel De, El ingenioso hidalgo Don Quijote de La Mancha, ed. de Luis Andrés Murillo, Madrid: Castalia, 1978.

Cresswell, Tim, Place: A Short Introduction, Malden: Mass Blackwell Publishing, 2004.

El libro del cavallero Çifar, ed. de Marilyn Olsen, Madison: Hispanic Seminary of Medieval Studies, 1984.

Escobar Fuentes, Samantha, Felipe Ríos Baeza, José Sánchez Carbó, Alicia V. Ramírez Olivares, Alejandro Palma Castro y Alejandro RaMÍrez LÁMBARRY, “Topoiesis de las instancias enunciativas”, Romance Quarterly, 64:1, 2017, 28-36.

Frank, Joseph, "Spatial Form in Modern Literature", The Sewanee Review, 53:4, 1945, 643-653.

García Berrio, Antonio, Teoría de la literatura: la construcción del significado, Madrid: Cátedra, 1989.

GenetTe, GÉrARd, Figuras III, Barcelona: Lumen, 1989.

Genette, GÉrard, Nouveau discours du récit, Paris: Seuil, 1983.

Guerreau, Alain, "El significado de los lugares en el Occidente medieval: estructura y dinámica de un "espacio" específico", en Enrico Castelnuovo y Giuseppe Sergi (dirs.), Arte e historia en la Edad Media I. Tiempos, espacios, instituciones, Madrid: Akal, 2009, 181-213.

Hanawalt, Barbara y Michal Kobialka (eds.), Medieval Practices of Space, Minneapolis y London: University of Minnesota Press, 2000.

Heidegger, Martín, Ser y Tiempo, México: Fondo de Cultura Económica, 1971.

Higashi, Alejandro, "Algunos arquetipos clásicos y medievales del caballero", en Aurelio González y María Teresa Miaja de la Peña (eds.), Caballeros y libros de caballerías, México: Universidad Nacional Autónoma de México, 2008, 35-54.

Huizinga, Johan, El otoño de la Edad Media. Estudios sobre la forma de la vida y del espíritu durante los siglos XIV y XV en Francia y los Países Bajos, Madrid: Alianza, 1978. 
Kappler, Claude, Monstruos, demonios y maravillas a fines de la Edad Media, Madrid: Akal, 1986.

Kleindschmidt, Harald, Comprender la Edad Media. La transformación de ideas y actitudes en el mundo medieval, Madrid: Akal, 2000.

Lefebvre, Henri, La producción del espacio, Madrid: Capitan Swing, 2013.

Luna Mariscal, Karla Xiomara, El Baladro del sabio Merlín. La percepción espacial en una novela de caballerías hispánica, México: Universidad Nacional Autónoma de México, 2006.

Meinig, D. W., “The Beholding Eye: Ten Versions of the Same Scene”, en D.W. Meinig y John Brinckerhoff Jackson (eds.), The Interpretation of Ordinary Landscapes: Geographical Essays, New York: Oxford University Press, 1979, 33-48.

Mitchell, W. J. T., "Spatial Form in Literature: Toward a General Theory”, Critical Inquiry, 6, 1980, 539-567.

Nebrija, Elio Antonio, Vocabulario español-latino, ed. facsimilar, Madrid: Real Academia Española, 1951.

Palma Castro, Alejandro, José Sánchez Carbó, Alicia V. Ramírez Olivares, Felipe Ríos Baeza, Samantha Escobar Fuentes y Alejandro RaMÍREZ LÁMBARRY, “Topoiesis: procesos de espacialización en la literatura (crítica y metodología)", Romance Quarterly, 64:1, 2017, 1-12.

Pimentel, Luz Aurora, El relato en perspectiva, México: Siglo XXI-Universidad Nacional Autónoma de México, 1998.

Pimentel, Luz Aurora, El espacio en la ficción, México: Siglo XXI, 2001.

Pinet, Simone, “Para leer el espacio en el Poema de mio Cid: Breviario teórico”, $\mathrm{La}$ Corónica: A Journal of Medieval Hispanic Languages, Literatures, and Cultures, 33:2, 2005, 195-208.

Rodilla, María José, “Aquella cibdat ribera de la mar. La representación de las ciudades en El caballero Zifar", en Concepción Company Company, Aurelio Gónzalez y Lilian von der Walde Moheno (eds.), Aproximaciones y revisiones medievales, historia, lengua y literatura, México: El Colegio de México, Universidad Nacional Autónoma de México, Universidad Autónoma Metropolitana, 2013, 395-404.

San Pedro, Diego de, Cárcel de amor, ed. de Carmen Parrilla, Barcelona: Crítica, 1995.

SLAWINSKI, JANUSZ, "El espacio en la literatura: distinciones elementales y evidencias introductorias", en Textos y contextos, sel. y trad. de Desiderio Navarro, t. II, La Habana: Arte y Cultura, 1989, 265-287.

Tally, Robert T. JR., Spatiality, London y New York: Routledge, 2013.

Tuan, YI-Fu, "Space and Place: Humanistic Perspective", Progress in Geography, 6, 1974, 211-252. 
Tuan, YI-Fu, Topophilia. A Study of Environmental Perception, Attitudes, and Values, New York: Columbia University Press, 1974.

TuAn, YI-Fu, "Language and the Making of Place: A Narrative-Descriptive Approach", Annals of the Association of American Geographers, 81:4, 1991, 684-696.

Tuan, YI-Fu, Space and Place. The Perspective of Experience, Minneapolis: University of Minnesota Press, 2001.

Velázquez Elizalde, Alejandro, "Función y sentido de los espacios exteriores en Tirant lo Blanch: ciudades, plazas, posadas e iglesias", Tirant, 10, 2007, s/p.

Velázquez Elizalde, Alejandro,"Función y sentido de los espacios en la corte en Tirant lo Blanch: Aposentos privados, salas de consejo, huertos y espacios públicos del palacio", Tirant, 11, 2008, 157-194.

Zoran, Gabriel, "Towards a Theory of Space in Narrative”, Poetics Today, 5:2, 1984, 309-335.

Zubiaurre, María Teresa, El espacio en la novela realista. Paisajes, miniaturas, perspectivas, México: Fondo de Cultura Económica, 2000.

Zumthor, Paul, La medida del mundo, Madrid: Cátedra, 1994. 